\title{
Degree of Male Mobility as a Risk Factor for HIV in High In-Migration Districts of Maharashtra, India
}

\author{
Dipak Suryawanshi ${ }^{*}$, Bidhubhushan Mahapatra², Varun Sharma ${ }^{1}$, K. Anil Kumar ${ }^{1}$, \\ Niranjan Saggurti ${ }^{2}$, Shalini Bharat ${ }^{1}$ \\ ${ }^{1}$ School of Health Systems Studies, Tata Institute of Social Sciences, Mumbai, India \\ ${ }^{2}$ HIV and AIDS Program, Population Council, New Delhi, India \\ Email: "deep.suryawanshi@gmail.com
}

Received 26 July 2014; revised 20 August 2014; accepted 15 September 2014

Copyright (C) 2014 by authors and Scientific Research Publishing Inc.

This work is licensed under the Creative Commons Attribution International License (CC BY). http://creativecommons.org/licenses/by/4.0/

C) (i) Open Access

\begin{abstract}
Background: Mobile males are vulnerable to HIV and are potential bridge for HIV transmission to their sex partners, including spouses. To understand how mobility accentuates vulnerability to HIV, we assessed the association of degree of male mobility with paid sex, alcohol use and condom use at all places visited by migrants in past two years. Methods: A cross-sectional survey was done among male migrant workers [ $n=2991]$ in five high in-migration districts of Maharashtra in India during 2007-08. Results: Multivariate logistic regression analysis revealed that higher mobility [moving 3+ places in the past two years] was associated with "sexual debut" in paid sex [3.7\% Vs $6.9 \%, A O R=1.70, p<0.001]$ and having sex with sex worker at the current place of destination $[8.7 \%$ Vs $16.9 \%, A O R=2.10, p<0.001]$, at the previous place of destination $[7.2 \% \mathrm{Vs} 15.1 \%$, AOR $=2.05, \mathrm{p}<0.001]$, and at the place of origin [0.6\% Vs $1.6 \%, \mathrm{AOR}=2.31, \mathrm{p}<0.001]$. However, higher mobility was associated with unpaid sex with non-marital female partners $[28.4 \%$ Vs $37.2 \%$, AOR $=1.48, p<0.001]$ and less consistent condom use at the current place $[26.6 \%$ Vs $23.4 \%$, AOR $=0.45, \mathrm{p}<0.05]$ as well as at place of origin $[12.2 \% \mathrm{Vs} 7.2 \%$, AOR $=0.48, \mathrm{p}<0.01]$. In addition, alcohol use prior to sex was more among more mobile migrants relative to less mobile migrants at current place $[6.1 \%$ Vs $11.2 \%$, AOR $=1.82, \mathrm{p}<0.001]$ and previous place $[7.0 \%$ Vs $13.0 \%$, AOR = $1.77, p<0.001]$ of destination. Conclusion: Findings suggest that compared to the less mobile, highly mobile men report higher HIV risk behaviours: paid sex, alcohol use prior to paid sex and inconsistent condom use, at all locations along the routes of mobility. Interventions need to target men who are highly mobile along the routes of mobility and not at destination sites alone.
\end{abstract}

\section{Keywords}

Male Mobility, Alcohol Use, Condom Use, Degree of Mobility, HIV, India

\footnotetext{
${ }^{*}$ Corresponding author.
}

How to cite this paper: Suryawanshi, D., Mahapatra, B., Sharma, V., Kumar, A., Saggurti, N. and Bharat, S. (2014) Degree of Male Mobility as a Risk Factor for HIV in High In-Migration Districts of Maharashtra, India. World Journal of AIDS, 4, $346-355$. http://dx.doi.org/10.4236/wja.2014.43041 


\section{Introduction}

In recent studies male migrants are widely acknowledged as important facilitators of HIV transmission [1]-[4]. Migration status of males is strongly associated with risky sexual practices [multiple sexual partners, ignorance about condom use, inconsistent use of condom and substance use prior to sex] in India and elsewhere [5]-[7]. Socio-economic and psychological factors [contractual system of labour, limited knowledge about HIV and other STIs, and low self-perceived risk of HIV] escalate their vulnerability to HIV and other STIs [8] [9]. Additionally, living arrangements of male migrants add to their vulnerability to HIV [10]. Studies related to migration have generally focused on long term movements. The role played by short-term, temporary movements [henceforth mobility] in influencing behavioural practices of migrants is not adequately explored, particularly in Indian context [9] [11]-[14]. These temporary movements form complex network of constant and frequent contacts with partners and serve as channel not only for economic gains through remittances but also of many diseases [15] [16]. Various studies have attempted to capture the impact of mobility and suggested that it may lead to greater propensity of high risk sexual behavior among migrants exposing not only them but also their casual and regular partners such as, spouses, to HIV and other STIs [17] [18]. Mobility increases the number of sexual partners, sexual networks, likelihood of unsafe sexual practices and the connectivity of geographically delimited/closed sexual networks [19]. Mobile men with non-resident spouses are more likely to be indulging in multiple sex partners than their counterpart [11]. Hence, it may be argued that temporary movements of migrants is an important dimension for understanding the vulnerability related to HIV risk because these movements form multi-local social networks which in turn create opportunities for continued sexual networking [20]-[22]. Indian studies have not adequately explored the sexual and other lifestyle behavior of migrants in relation to mobility [23]. Available research is generally focused on life style and sexual behavior of active or returning migrants at current place of destination or place of origin [12] [13]. The aspect of mobility which captures the dynamic and fluid nature of migration is largely ignored in these studies. This paper attempts to fill this gap by focusing on the role of "mobility" in HIV vulnerability. It examines the association between degree of mobility and HIV related risky behavior [sexual behavior and alcohol use] among male migrants across their current place of destination, previous places visited and place of origin.

\section{Methodology}

\subsection{Study Settings}

The data used in this paper are derived from a behavioural cross-sectional survey of male migrant workers conducted by Tata Institute of Social Sciences and Population Council during June 2007 to September 2008. The participants were recruited from five districts [Mumbai, Nagpur, Nashik, Pune and Thane] of Maharashtra state with high rates of in-migration, as per the 2001 census of India [24].

\subsection{Sampling Design}

A two-stage systematic sampling procedure was adopted in selected migrant worker residential colonies [either organized labour colonies or illegally occupied land where small hutments were made for living] and worksites. District maps were used to list all migrant worker residential areas and worksites and to define and select the clusters within these sites. At Stage-1, clusters were selected systematically from the list and subsequently at Stage-2, houses were selected using systematic sampling method. Migrant men from the chosen houses were sampled systematically. For the selection of migrants at the workplace, a facility-based procedure was used. If the facility listed their male migrant workers, the lists were used to select the men for interview systematically. Otherwise, men were selected from the areas where they work or loiter.

\subsection{Eligibility and Recruitment}

The eligibility criteria for inclusion were age 18 years or older, and having moved to at least two places in the past 2 years for work. The final sample size was 2991. Personal interviews were conducted by trained multilingual investigators in private locations or at workplaces. Verbal consent was obtained from all respondents. Ethical approval for the study was obtained from the Institutional Review Board [IRB] of the Population Council, New Delhi, India. 


\subsection{Measures}

\subsubsection{Socio-Demographic Measures}

Socio-demographic measures included questions about age, educational attainment, current marital status, and wife's resident status [Yes/No]. Occupational status of the male migrant workers was captured under the following categories: construction work, market place, loading and unloading, daily wage work, industrial work, stone cutting, and others. The current marital status and current residence with wife was combined to create a composite variable with categories: currently married and staying with wife, currently married and wife is at native place. State of origin was coded to indicate high/low HIV prevalence states: " $0=$ HIV low prevalence state" [i.e. Uttar Pradesh, Bihar, Chhattisgarh, West Bengal etc.]; "1 = HIV high prevalence Maharashtra state”; and "2 = HIV high prevalence other states” [i.e. Andhra Pradesh, Karnataka, and Tamilnadu] [25]-[28].

\subsubsection{Migration and Mobility Measure}

The level of mobility was the key independent variable for the analysis and was derived from the survey item that asked how many different places the respondent had moved/visited in the past 2 years for work related purposes or prior to the current destination. Those indicating fewer than three places were coded as " $0=$ less mobile" and those indicating three or more places were coded as " 1 = more mobile". The survey instrument also gathered information on duration since migration [in years]: "When was the first time you moved out from the native place for job/work?”

\subsubsection{Sexual Risk Behavior Measures}

Sexual behavior questions included information on type of sexual partners [female sex workers, non-spousal/ non-marital female sex partners], frequency of condom use with those partners, and alcohol use prior to sex with each partner type at 3 sites: destination sites [past 12 months], previous place of destination and place of origin [past 24 months]. Reference period for condom use with each partner type was fixed at "last time" and "past 6 months". For the purpose of analysis consistent condom use is defined as the use of a condom every time that the respondent had sex with any partner. Dependent measures of sexual risk behavior were created as follows: number of sexual partners, sex with a sex worker, and sex with non marital female partner in place of origin, destination and previous place visited.

\subsubsection{Alcohol/Substance Use Measure}

Alcohol use prior to or during sex was measured at each site [destination, previous visited place, place of origin] with each partner type with reference period of 1 month prior to the survey [past 30-day use].

\subsection{Statistical Analysis}

Calculation of proportions and Chi-square tests were carried out to detect differences in HIV risk indicators by levels of mobility among sampled male migrant population. The odds ratios were used to measure the association between degree of mobility and HIV related risk behavior indicators using logistic regression models [adjusting for socio-demographic characteristics like age, education, income, occupation and marital status to control the confounding effect of demographics with outcome variable]. All statistical analyses were conducted using SPSS 17.0.

\section{Results}

\subsection{Socio-Demographic Characteristics}

Of the sampled population [ $N=2991$ ], almost $3 / 5^{\text {th }}$ of the migrants [ $59.8 \%, n=1790$ ] were "less mobile" and remaining [40.2\%, $\mathrm{n}=1201$ ] were "more mobile" [i.e. had moved to 3 or more places in past 2 years]. Migrants were generally in their mid twenties [Mean age 24.7 years] and most had received 7 - 8 years of schooling (Table 1); the "more mobile" being somewhat better educated. Half [50.7\%] of the male migrants were married which splits into a majority of [33.9\%] living away from their wives and only $16.8 \%$ living with their wives. A significantly higher proportion [84.6\%] of the 'less mobile' among the currently married reported living away from their wives for more than 7 months in a year compared to the more mobile [48.7\%]. In short, a higher proportion of the less mobile reported longer periods of uninterrupted spousal separation. Nearly half of the male 
Table 1. Sociodemographic characteristics of sampled male migrant population by degree of mobility, Maharashtra, India [N $=2991]$.

\begin{tabular}{|c|c|c|c|c|}
\hline \multirow{2}{*}{ Socio-Demographic Characteristics } & $\begin{array}{c}\text { Total } \\
{[\mathrm{N}=2991]}\end{array}$ & $\begin{array}{l}\text { Less Mobile } \\
{[n=1790]}\end{array}$ & $\begin{array}{c}\text { More Mobile }^{a} \\
{[n=1201]}\end{array}$ & \multirow{2}{*}{ p-Value ${ }^{b}$} \\
\hline & $\%$ & $\%$ & $\%$ & \\
\hline
\end{tabular}

\section{Age Group [in years]}

$<0.001$

$\leq 20$ years

$$
18.7
$$

20.7

15.7

21 - 25 years

46.3

43.1

51.0

$25+$ years

Mean ( \pm S.D.) age

$24.7[ \pm 4.6]$

$24.7[ \pm 4.7]$

$24.7[ \pm 4.5]$

0.52

Educational Status

Primary school [1 - 4] or none

21.8

20.8

Secondary school [5 - 8]

46.7

48.0

44.8

High school and above [9+]

30.2

34.4

Average grade completed [ \pm S.D.]

$7.6[ \pm 2.5]$

$7.4[ \pm 2.4]$

$7.7[ \pm 2.7]$

$<0.05$

Current Marital Status

Unmarried

49.2

48.9

49.8

Currently married and staying with wife

16.8

13.5

21.8

Currently married but wife is at native place

37.7

Duration of Stay without Wife [in Months] ${ }^{\mathrm{c}}$

1 - 6 months

40.7

14.8

32.2

52.4

$<0.01$

Occupation

Hamalis [loader/unloader]

4.0

Daily wage laborers

Industry workers

Stone cutters

Others

11.1

6.2

3.0

47.9

45.5

4.0

6.2

10.5

12.1

Native State of Respondent

HIV low prevalence state ${ }^{\mathrm{d}}$

82.0

84.7

77.9

Maharashtra

12.0

9.0

16.6

6.0

6.3

0.051

$<0.01$

$<0.01$

49.0

31.1

7.6

HIV high prevalence state $\mathrm{e}^{\mathrm{e}}$

5.5

aThe degree of mobility is defined in two categories: "less mobile”, i.e. moved to less than 3 places in past 2 years and "more mobile”, i.e. moved 3 or more places in past 2 years; ${ }^{b}$-value is generated using Wald-Chi-square test; 'Among those migrants who are currently married and not staying with wife [n = 1015]; ${ }^{\mathrm{d}}$ This includes the low HIV prevalence states like Bihar, Chhattisgarh, Madhya Pradesh, Uttar Pradesh etc.; ${ }^{\mathrm{T}}$ This includes high HIV prevalence states like Andhra Pradesh, Karnataka and Tamil Nadu.

migrants [47.0\%] were industry workers and about one fourth [28\%] were construction workers. The sampled migrants were predominantly from low HIV prevalence states like Uttar Pradesh, Bihar, Chhattisgarh and Mad- 
hya Pradesh [82\%], with only $12 \%$ coming from within Maharashtra state; which is also a high prevalence state and a much smaller percentage [6\%] coming from high HIV prevalence states of Andhra Pradesh, Tamil Nadu and Karnataka. A comparatively higher proportion of the less mobile migrants were from low HIV prevalence states [85\%]; while among those more mobile 78\% belonged to low prevalence states followed by Maharashtra with less than one fifth [17\%] and remaining from other high HIV prevalence states [5.5\%].

\subsection{Alcohol Use}

Nearly $45 \%$ of the study sample reported alcohol use in past 30 days; a significantly higher proportion among them more mobile sample than those less mobile [p $<0.001$, Table 2]. Further, a significantly higher proportion of the more mobile sample reported alcohol use prior to sex at both current site [11.2\%] and at previous destination site [13\%] as compared to the less mobile [6\% \& 7\% respectively].

\subsection{Sexual Risk Behavior}

Among unmarried male migrants, more than half [55.3\%] reported ever having sex in their life and among those who had sex, the proportion was more among "more mobile" migrants as compared to "less mobile" migrants [p $<0.001$, Table 3]. Only $5 \%$ of the total sampled migrants, among them a significantly higher proportion of the more mobile, reported "sex worker" as their first sexual partner in life [p < 0.001]. Migration and mobility, however, seem to change this pattern. The proportion of male migrants reporting visit to female sex workers showed an increase between place of origin [1\%], previous destination [10.4\%] and current destination [12\%]. Although both the less mobile and the more mobile reported an increase in visits to FSWs across sites visited, it was significantly substantial in the case of more mobile migrants at each site as compared to the less mobile. Thus, at each site nearly twice as many migrants who are more mobile reported visiting FSWs in comparison to those less mobile. However, sex with non-marital sex partner other than spouse such as girl friends or casual partner shows the reverse trend.

While nearly one third [31.9\%] of the migrants reported sex with non-marital partner at place of origin; this reporting was higher among more mobile [37.2\%] as compared to less mobile [28.4\%] male migrants and this proportion reduced progressively from the previous visited site to the current place of destination. However, the difference between the less mobile and more mobile migrants is maintained with a higher proportion of the latter reporting sexual behavior with a non-marital partner than the former. This suggests that "degree of mobility" is strongly associated with HIV-related sexual behaviours not only at the destination places but also at the place of origin. It also suggests that "more mobile" men are at higher risk of acquiring HIV infection due to their multipartnering sexual relationship at all sites: the current/previous place and place of origin.

\subsection{Condom Use Behaviours}

Consistent condom use [CCU] with FSWs and non-marital female partners ranged from $9.8 \%$ to $83.0 \%$ across the current/previous destination and place of origin. CCU was higher with paid partners such as FSWs as compared to with non-paid partners (Table 4). The proportion of "more mobile" migrants using condoms consistent-

Table 2. Degree of mobility and alcohol use across three different locations where migrant visited/worked in the past two years: current \& previous destination place and place of origin, Maharashtra, India [N = 2991].

\begin{tabular}{|c|c|c|c|c|}
\hline \multirow{2}{*}{ Alcohol Use Behaviors ${ }^{a}$} & $\begin{array}{c}\text { Total } \\
{[\mathrm{N}=2991]}\end{array}$ & $\begin{array}{c}\text { Less Mobile }^{\mathrm{b}} \\
{[\mathrm{n}=1790]}\end{array}$ & $\begin{array}{c}\text { More Mobile } \\
{[\mathrm{n}=1201]}\end{array}$ & $\mathbf{A O R}^{\mathrm{c}}[95 \% \mathrm{CI}]$ \\
\hline & $\%$ & $\%$ & $\%$ & \\
\hline Current alcohol use, past 30 days & 44.8 & 37.5 & 55.5 & $2.14^{* *}[1.82-2.52]$ \\
\hline Alcohol use prior to sex, current place of destination & 8.2 & 6.1 & 11.2 & $1.82^{* *}[1.38-2.39]$ \\
\hline $\begin{array}{l}\text { Alcohol use prior to sex, } \\
\text { previous place of destination }\end{array}$ & 9.4 & 7.0 & 13.0 & $1.77^{* *}[1.38-2.28]$ \\
\hline Alcohol use prior to sex, at the place of origin & 1.1 & 1.1 & 1.1 & $1.12[0.54-2.34]$ \\
\hline
\end{tabular}

${ }^{\mathrm{a}}$ Dependent variables: Current alcohol use $\left[0=\right.$ No, $1=$ Yes]; Alcohol use prior to sex [(by routes of mobility) $0=$ No, $1=$ Yes]; ${ }^{b}$ Reference category; c Controlled for age, age square [to check the effect of curvilinearity of age], education, marital status, religion, occupation, native state and duration of migration of the respondent. AOR: Adjusted odds ratio; 95\% CI: 95\% Confidence interval; ${ }^{*} \mathrm{p}<0.05 ;{ }^{* *} \mathrm{p}<0.01$. 
Table 3. Male migrant’s sexual risk behavior across the places visited by their degree of mobility.

\begin{tabular}{|c|c|c|c|c|}
\hline \multirow[t]{2}{*}{ Dependent Variables ${ }^{\mathrm{a}}$} & $\begin{array}{c}\text { Total } \\
\text { Sample } \\
{[N=2991]}\end{array}$ & $\begin{array}{l}\text { Less Mobile }^{b} \\
\quad[n=1790]\end{array}$ & $\begin{array}{c}\text { More } \\
\text { Mobile } \\
{[\mathrm{n}=1201]}\end{array}$ & \multirow[t]{2}{*}{ AOR $[95 \% \mathrm{CI}]$} \\
\hline & $\%$ & $\%$ & $\%$ & \\
\hline $\begin{array}{l}\text { Ever had sex-reported by “unmarried” } \\
\text { male migrants }{ }^{\mathrm{c}}\end{array}$ & 55.3 & 50.3 & 62.5 & $1.50^{* *}[1.17-1.94]$ \\
\hline "Sex worker" as first sexual partner in life & 5.0 & 3.7 & 6.9 & $1.70^{* *}[1.20-2.40]$ \\
\hline \multicolumn{5}{|l|}{ At Current Place of Destination ${ }^{d}$} \\
\hline Had sex with sex worker in past 1 year & 12.0 & 8.7 & 16.9 & $2.10^{* *}[1.62-2.70]$ \\
\hline Had sex with non-marital female partner in past 1 year & 7.5 & 5.3 & 10.7 & $2.36^{* *}[1.72-3.23]$ \\
\hline $\begin{array}{l}\text { Had sex with } 1+\text { non-marital } \\
\text { female partner in past } 1 \text { year }\end{array}$ & 2.2 & 1.6 & 3.0 & $1.97^{*}[1.11-3.49]$ \\
\hline \multicolumn{5}{|l|}{ At Previous Place of Destination ${ }^{\mathrm{e}}$} \\
\hline Had sex with female sex worker & 10.4 & 7.2 & 15.1 & $2.05^{* *}[1.60-2.62]$ \\
\hline Had sex with non-marital female partner & 15.5 & 12.5 & 20.0 & $1.62^{* *}[1.32-2.00]$ \\
\hline Had sex with $1+$ non-marital female partner & 10.6 & 8.3 & 14.1 & $1.59^{* *}[1.25-2.03]$ \\
\hline \multicolumn{5}{|l|}{ At the Place of Origin ${ }^{f}$} \\
\hline Had sex with female sex worker & 1.0 & 0.6 & 1.6 & $2.31^{*}[1.08-4.94]$ \\
\hline Had sex with non-marital female partner & 31.9 & 28.4 & 37.2 & $1.48^{* *}[1.25-1.74]$ \\
\hline Had sex with $1+$ non-marital female partner & 6.1 & 5.9 & 6.4 & $1.07[0.78-1.46]$ \\
\hline
\end{tabular}

${ }^{\mathrm{a}}$ Dependent variables: Had sex with female sex worker [(by routes of mobility) $0=$ No, $1=$ Yes]; Had sex with non-marital female partner [(by routes of mobility) $0=$ No, $1=$ Yes]; Had sex with $1+$ non-marital partner [(by routes of mobility) $0=$ No, $1=$ Yes]; ${ }^{b}$ Reference category; ${ }^{\mathrm{C}}$ Among the unmarried/ single male migrants [ $n=1466$ ]. Non-marital female partner is defined as partner other than female sex worker or partner other than spouse/female sex worker for married male migrants. This definition is used consistently at all the places, i.e. current/previous place of destination and place of origin; ${ }^{\mathrm{d}}$ Controlled for age, age square [to check the effect of curvilinearity of age], education, marital status, religion, occupation, native state, duration of stay at the current place of destination and duration of migration of the respondent; ${ }^{e}$ Controlled for age, age square [to check the effect of curvilinearity of age], education, marital status, religion, occupation, native state, duration of stay at previous place of destination and duration of migration of the respondent; ${ }^{\mathrm{f} C o n t r o l l e d ~ f o r ~ a g e, ~ a g e ~ s q u a r e ~[t o ~ c h e c k ~ t h e ~ e f f e c t ~ o f ~ c u r v i l i n e a r i t y ~ o f ~ a g e], ~ e d u c a t i o n, ~ m a r i t a l ~ s t a t u s, ~ r e l i g i o n, ~ o c c u p a t i o n, ~ n a t i v e ~ s t a t e, ~}$ frequency of visiting native place [place of origin] and duration of migration of the respondent. AOR: Adjusted odds ratio; 95\% CI: 95\% confidence interval; ${ }^{*} \mathrm{p}<0.05 ;{ }^{* *} \mathrm{p}<0.01$

Table 4. Consistent condom use among the male migrants across the routes of mobility by degree of mobility.

\begin{tabular}{|c|c|c|c|c|}
\hline \multirow[t]{2}{*}{ Consistent Condom Use with a } & $\begin{array}{c}\text { Total } \\
\text { Sample }\end{array}$ & Less Mobile $^{b}$ & $\begin{array}{c}\text { More } \\
\text { Mobile }\end{array}$ & \multirow[t]{2}{*}{$\mathbf{A O R}^{\mathbf{c}}[95 \% \mathrm{CI}]$} \\
\hline & $\%$ & $\%$ & $\%$ & \\
\hline $\begin{array}{l}\text { Female sex worker, at current place of destination } \\
{[\mathrm{n}=359]}\end{array}$ & $\begin{array}{c}83.0 \\
{[298 / 359]}\end{array}$ & $\begin{array}{c}84.6 \\
{[132 / 156]}\end{array}$ & $\begin{array}{c}81.8 \\
{[166 / 203]}\end{array}$ & $0.89[0.46-1.71]$ \\
\hline $\begin{array}{l}\text { Non-marital female partner, at current place of destination } \\
{[\mathrm{n}=222]}\end{array}$ & $\begin{array}{c}24.8 \\
{[55 / 222]}\end{array}$ & $\begin{array}{c}26.6 \\
{[25 / 94]}\end{array}$ & $\begin{array}{c}23.4 \\
{[30 / 128]}\end{array}$ & $0.45^{*}[0.20-0.99]$ \\
\hline $\begin{array}{l}\text { Any non-marital partner, at previous place of destination } \\
\text { [n = 463] }\end{array}$ & $57.7[267 / 463]$ & $\begin{array}{c}56.1 \\
{[125 / 223]}\end{array}$ & $\begin{array}{c}59.2 \\
{[142 / 240]}\end{array}$ & $1.23[0.80-1.88]$ \\
\hline $\begin{array}{l}\text { Any non-marital partner, at the place of origin } \\
{[\mathrm{n}=955]}\end{array}$ & $\begin{array}{c}9.8 \\
{[94 / 955]}\end{array}$ & $\begin{array}{c}12.2 \\
{[62 / 508]}\end{array}$ & $\begin{array}{c}7.2 \\
{[32 / 447]}\end{array}$ & $0.48^{* *}[0.28-0.82]$ \\
\hline
\end{tabular}

${ }^{\mathrm{a}}$ Dependent variables: Consistent condom use with female sex worker, at the current place of destination $[0=$ No, $1=$ Yes]; Consistent condom use with non-marital female partner, at the current place of destination [0 = No, $1=$ Yes]; Consistent condom use with any non-marital female partner [(at previous destined place and at the place of origin) $0=$ No, $1=$ Yes]; ${ }^{b}$ Reference category; ${ }^{\mathrm{c} C o n t r o l l e d ~ f o r ~ a g e, ~ a g e ~ s q u a r e ~[t o ~ c h e c k ~ t h e ~ e f f e c t ~ o f ~ c u r v i l i-~}$ nearity of age], education, marital status, religion, occupation, native state and duration of migration of the respondent. AOR: Adjusted odds ratio, 95\% CI: $95 \%$ confidence interval; ${ }^{*} \mathrm{p}<0.05 ;{ }^{* *} \mathrm{p}<0.01$. 
ly with FSWs was less as compared to the "less mobile" migrants [81.8\% vs. 84.6\%; AOR = 0.91; 95\% CI: 0.48 1.75] at current place. The same trend was observed with non-marital female partner at the current destination. Moreover, at the current place of destination [26.6\% vs. $23.4 \%$; AOR $=0.45$; $95 \% \mathrm{CI}$ : $0.20-0.99$ ] and at the place of origin [7.2\% vs. $12.2 \%$; AOR $=0.53$; $95 \%$ CI: 0.31 - 0.91], "more mobile" migrants were found less likely to use condoms consistently with non-marital female partner as compared to those "less mobile".

\section{Discussion}

Studies among male migrants have mostly emphasized on the relationship between migration status and their sexual risk behaviour which puts them at a greater risk of acquiring HIV infection and a potential bridge population [5]-[7] [29]-[34]. Findings presented in this paper highlight the role of mobility in accentuating HIV related risk for male migrants. "More mobile" migrants reported higher proportion of risky sexual practices [visiting sex workers, sex with non-marital female partners, substance use prior to sex and inconsistent condom use] at all sites of movement [current, previous destination place and place of origin]. The study documented that "degree of mobility" is an influential factor in determining the sexual behavior of male migrants at destination as well as place of origin. At destination [current as well as previous], the more mobile migrants were more likely to be engaging in paid sex than their counterpart. Likewise, at place of origin, more mobile migrants are more likely to be engaging in unpaid sex. In Indian context, this finding is in line with the other studies [12] [13]. The findings suggest that returning migrants continue to engage in sexual practices with unpaid non-marital female partners. Additionally, inconsistent condom use, especially among more mobile migrants during such sexual encounters, facilitates spread of HIV infection and other STIs. This is supported by the fact that in the recent HIV estimates, a higher rate of HIV incidence was reported among anti-natal clinic [ANC] attendees at the places which are major source of migrants [14]. Moreover, a small proportion of migrants have also reported "sex worker" as their first sexual partner in life, which is basically the measure of sexual debut for paid sex in the destination sites. This early exposure to paid sex along with inconsistent condom use at destination sites makes them vulnerable to HIV/STI infection. The proportion of these "risky" behaviours was observed more among migrants with higher degree of mobility.

A body of literature across the globe has shown "alcohol use prior to sex" as a lead to unprotected sex with casual partners [12] [35] which expose them to HIV risk [36] [37]. Studies in India have shown high alcohol consumption among mobile men increasing their risk of STI infections due to inconsistent condom use under the influence of alcohol [38] [39]. Additionally, a population-based and hospital-based study in Andhra Pradesh concluded that consumption of alcohol prior to sex was a key determinant of sexual risk [unprotected sex and anal sex]. The study also recommended the reduction in consumption of alcohol prior to sex to prevent HIV infection among married and unmarried men [40] [41]. The current paper reports the proportion of respondents reporting consumption of alcohol prior to sex to be almost double among the 'more mobile' migrants than their counterpart. Association between use of substance and risky sexual practices has been reported by earlier various studies [12] [42]. Various studies also document the reasons for use of alcohol prior to sexual act as peer pressure, to ignite sexual sensation, enhancing sexual performance, sexual aggression and pleasure, to overcome emotional distress and muster courage to purchase sex services of FSWs etc. [43]-[48]. Exploring high mobility in relation to alcohol use prior to sex, the post-hoc analysis suggests that the young male migrants in the age group of 21 - 25 years, unmarried and belonging to lower economic strata, indulge more in alcohol use prior to sex. Aforementioned reasons are likely to be contributing factors resulting in risky sexual practices to prove masculinity [49]. Hence, HIV prevention programmes should target this sub-group of male migrants and disseminate information about the ill consequences of using alcohol prior and during sexual act. Rehabilitation programmes may also be an effective way to reduce alcohol consumption among this group.

Consistent condom use [CCU] is an important measure of safer sexual practices. However, the study reported same level of consistent condom use, though statistically non-significant [p > 0.05] among both groups of interest [more and less mobile]. Yet, CCU with FSWs at current place of destination was relatively low among more mobile than their counterparts. Again, at the place of origin, CCU was significantly low among more mobile migrants. Relatively low CCU among more mobile migrants puts their sexual partner at an escalated risk of HIV and other STIs. Various studies have documented the reasons for inconsistent condom use among male migrants as: lack of sexual knowledge and education, low level of education, long duration of separation from spouses and alcohol consumption which impairs the decision of using condoms [50] [54]. These factors should be duly dealt with while formulating the intervention strategies for male migrants. In addition, irrespective of degree of 
mobility, more male migrants were indulging in paid sex at current destination place than previous place and place of origin [12.0\%, $10.7 \%$ and $1.0 \%$ respectively]. Conversely, indulgence of migrants in unpaid sex with non-marital female partners was high at the place of origin as compared to current and previous destination [31.9\%, 7.5\% and 15.5\% respectively]. The findings are consistent with other Indian studies [13] [23].

The results of this study must be interpreted keeping in mind certain limitations. From programme perspective, one limitation of the study is that it is difficult to identify and target unpaid sexual partners [non-spousal] of male migrants. Secondly, the results are specific to male migrants' community in Maharashtra state. It is quite possible that the sexual behavior of male migrants may vary in other high HIV prevalence states. Likewise, the possibilities are that the behavior may vary among mobile and non-mobile men considerably across the state. Another limitation is that duration of exposure for risky behavior may not have been uniform across different sites visited. Recall bias may also be a limitation considering that highly mobile population is also less likely to remember many details of their risky behavior.

Despite these caveats, this study contributes to the growing body of migration and mobility related studies. Most of the surveys and studies ignore the short term frequent movements of mobile male population and fail to acknowledge this sub-group as potential bridging population. This study brings the mobility factor to forefront and relates it with the risky sexual behavior among male migrants along the routes of migration. The study findings suggest that in addition to destination areas, the "place of origin" and "other intermittent" sites are also crucial geographical locations for intervention in response to HIV. Study recommends that prevention programmes should target the more mobile males specifically calling attention to gathering more details about nature of work and working conditions.

The findings of this study also emphasize on the need to develop an effective research agenda on male mobility and refine survey tools to capture the aspect of mobility more precisely. Questions related to short term movements can also be incorporated in the census or national sample survey interview schedules such as, National Sample Survey [NSSO] to capture adequate information regarding the degree of mobility among males. Detailed and reliable information will help researchers and policy makers to design more effective programs for mobile population groups in the country.

\section{Acknowledgements}

This paper was written as part of a mentorship program under the Knowledge Network Project of the Population Council, which is a grantee of the Bill and Melinda Gates Foundation through Avahan, its India AIDS Initiative. The views expressed herein are those of the authors and do not necessarily reflect the official policy or position of the Bill and Melinda Gates Foundation and Avahan.

\section{References}

[1] Singh, S.K., et al. (2006) Dynamics of Social Networking, Drug Abuse and Risk Behaviour to STD and HIV/AIDS in India: A Case Study of Adult Male Migrants in Surat, India. In: Pandey, A., Ed., Bio-Statistical Aspects of Health and Population, Hindustan Publishing Corporation, New Delhi, 95-105.

[2] Halli, S., et al. (2007) Migration and HIV Transmission in Rural South India: An Ethnographic Study. Culture, Health \& Sexuality, 9, 85-94. http://dx.doi.org/10.1080/13691050600963898

[3] Verma, R., et al. (2007) Patterns and Implications of Male Migration for HIV Prevention Strategies in Andhra Pradesh. Technical Brief from Population Council India, No. 1. Population Council, New Delhi.

[4] Saggurti, N., et al. (2008) Patterns and Implication of Male Migration for HIV Prevention Strategies in Maharashtra, India. Technical Brief from Population Council India, No. 3. Population Council, New Delhi.

[5] Boerma, J.T., et al. (2002) Sociodemographic Context of the AIDS Epidemic in a Rural Area in Tanzania with a Focus on People's Mobility and Marriage. Sexually Transmitted Infections, 78, i97-i105. http://dx.doi.org/10.1136/sti.78.suppl_1.i97

[6] Shrestha, S.D. and Sundby, J. (2004) A Study on Sexually Transmitted Diseases (STD)/HIV/AIDS Risks of Migrants and Non-Migrants in a Mountainous District, Nepal. International AIDS Society, Bangkok.

[7] Wang, W., et al. (2010) Prevalence and Risks for Sexually Transmitted Infections among a National Sample of Migrants versus Non-Migrants in China. International Journal of STD AIDS, 21, 410-415. http://dx.doi.org/10.1258/ijsa.2009.008518

[8] Gupta, I. and Mitra, A. (1999) Knowledge of HIV/AIDS among Migrants in Delhi Slums. Journal of Health and Popu- 
lation in Developing Countries, 2, 26-32.

[9] Saggurti, N., et al. (2008) HIV Risk Behaviours among Contracted and Non-Contracted Male Migrant Workers in India: Potential Role of Labour Contractors and Contractual Systems in HIV Prevention. Aids, 22, S127-S136. http://dx.doi.org/10.1097/01.aids.0000343771.75023.cC

[10] Mishra, A. (2004) Risk of Sexually-Transmitted Infections among Migrant Men: Findings from a Survey in Delhi. Asian and Pacific Migration Journal, 13, 89-105.

[11] Saggurti, N., Schensul, S.L. and Verma, R.K. (2009) Migration, Mobility and Sexual Risk Behavior in Mumbai, India: Mobile Men with Non-Residential Wife Show Increased Risk. AIDS and Behavior, 13, 921-927. http://dx.doi.org/10.1007/s10461-009-9564-8

[12] Verma, R.K., et al. (2010) Alcohol and Sexual Risk Behavior among Migrant Female Sex Workers and Male Workers in Districts with High In-Migration from Four High HIV Prevalence States in India. AIDS and Behavior, 14, S31-S39. http://dx.doi.org/10.1007/s10461-010-9731-y

[13] Saggurti, N., et al. (2011) Male Migration and Risky Sexual Behavior in Rural India: Is the Place of Origin Critical for HIV Prevention Programs? BMC Public Health, 11, S6. http://dx.doi.org/10.1186/1471-2458-11-S6-S6

[14] Saggurti, N., et al. (2012) Male Out-Migration: A Factor for the Spread of HIV Infection among Married Men and Women in Rural India. PLoS ONE, 7, e43222. http://dx.doi.org/10.1371/journal.pone.0043222

[15] Singhanetra-Renard, A. (1981) Mobility in North Thailand: A View from within. In: Jones, G.W. and Richter, H.V., Eds., Population Mobility and Development: Southeast Asia and the Pacific, Australian National University, Canberra, 137-166.

[16] Hugo, G.J. (1982) Circular Migration in Indonesia. Population and Development Review, 8, 59-83. http://dx.doi.org/10.2307/1972690

[17] Kishamawe, C., et al. (2006) Mobility and HIV in Tanzanian Couples: Both Mobile Persons and Their Partners Show Increased Risk. Aids, 20, 601-608. http://dx.doi.org/10.1097/01.aids.0000210615.83330.b2

[18] Dodson, B. and Crush, J. (2003) Mobile Deathlihoods: Migration and HIV/AIDS in Africa. In: UNAIDS Project “AIDS in Africa: Scenarios for the Future".

[19] Guest, P. (1999) Overview of Population Mobility Situation in Asia and Its Implications for HIV/AIDS. International Congress on AIDS in Asia and the Pacific (5th ICAAP), Kuala Lumpur.

[20] Lurie, M., et al. (1997) Circular Migration and Sexual Networking in Rural Kwa Zulu/Natal: Implications for the Spread of HIV and Other Sexually Transmitted Diseases. Health Transition Review, 7, 17-27.

[21] Gupta, K. and Singh, S.K. (2002) Social Networking, Knowledge of HIV/AIDS and Risk-Taking Behaviour among Migrant Workers. International Union for the Scientific Study of Population (IUSSP) Regional Population Conference on Southeast Asia's Population in a Changing Asian Context, Bankok.

[22] Wang, W., et al. (2014) Networking Activities and Perceptions of HIV Risk among Male Migrant Market Vendors in China. AIDS and Behavior, 18, 142-151. http://dx.doi.org/10.1007/s10461-013-0473-5

[23] Ganju, D., Mahapatra, B. and Saggurti, N. (2013) Male Migrants' Non-Spousal Sexual Partnerships in the Place of Origin: An In-Depth Investigation in Two Rural Settings of India. Culture, Health \& Sexuality: An International Journal for Research, Intervention and Care, 15, 341-357.

[24] Registrar General of India (2001) Census of India: D Series (Migration Tables). Registrar General of India, New Delhi.

[25] National AIDS Control Organization and National Institute of Health and Family Welfare (2006) Annual HIV Sentinel Surveillance Country Report. Ministry of Health and Family Welfare, New Delhi.

[26] National AIDS Control Organization (2008) HIV Sentinel Surveillance and HIV Estimation in India 2007: A Technical Brief: Ministry of Health and Family Welfare. National AIDS Control Organization, New Delhi.

[27] Pandey, A., et al. (2009) Improved Estimates of India’s HIV Burden in 2006. Indian Journal of Medical Research, 129, 50-58.

[28] Pandey, A., et al. (2012) Estimate of HIV Prevalence and Number of People Living with HIV in India 2008-2009. BMJ Open, 2, Article ID: e000926. http://bmjopen.bmj.com/content/2/5/e000926

[29] Wolffers, I. and Fernandez, I. (1995) Migration and AIDS. The Lancet, 346, 1303. http://dx.doi.org/10.1016/S0140-6736(95)91908-2

[30] George, S., et al. (1997) A Case-Control Analysis of Risk Factors in HIV Transmission in South India. Journal of Acquired Immune Deficiency Syndromes and Human Retrovirology, 14, 290-293. http://dx.doi.org/10.1097/00042560-199703010-00014

[31] Bronfman, M.N., et al. (2002) Mobile Populations and HIV/AIDS in Central America and Mexico: Research for Action. Aids, 16, S42-S49. http://dx.doi.org/10.1097/00002030-200212003-00007 
[32] Lagarde, E., et al. (2003) Mobility and the Spread of Human Immunodeficiency Virus into Rural Areas of West Africa. International Journal of Epidemiology, 32, 744-752. http://dx.doi.org/10.1093/ije/dyg111

[33] Hu, Z., et al. (2006) HIV-Related Sexual Behavior among Migrants and Non-Migrants in a Rural Area of China: Role of Rural-to-Urban Migration. Public Health, 120, 339-345. http://dx.doi.org/10.1016/j.puhe.2005.10.016

[34] Coffee, M., Lurie, M.N. and Garnett, G.P. (2007) Modeling the Impact of Migration on the HIV Epidemic in South Africa. Aids, 21, 343-350. http://dx.doi.org/10.1097/QAD.0b013e328011dac9

[35] Staton, M., et al. (1999) Risky Sex Behavior and Substance Use among Young Adults. Health \& Social Work, 24, 147154. http://dx.doi.org/10.1093/hsw/24.2.147

[36] Mataure, P., et al. (2002) Alcohol Use and High-Risk Sexual Behavior among Adolescents and Young Adults in Harare, Zimbabwe. AIDS and Behavior, 6, 211-219. http://dx.doi.org/10.1023/A:1019835723404

[37] Dunkle, K.L., et al. (2004) Transactional Sex among Women in Soweto, South Africa: Prevalence, Risk Factors and Association with HIV Infection. Social Science \& Medicine, 59, 1581-1592. http://dx.doi.org/10.1016/j.socscimed.2004.02.003

[38] Gupta, K., Vaidehi, Y. and Majumder, N. (2010) Spatial Mobility, Alcohol Use, Sexual Behavior and Sexual Health among Males in India. AIDS and Behavior, 14, S18-S30. http://dx.doi.org/10.1007/s10461-010-9738-4

[39] Pandey, A., et al. (2012) Alcohol Use and STI among Men in India: Evidences from a National Household Survey. Indian Journal of Community Medicine, 37, 95-100. http://dx.doi.org/10.4103/0970-0218.96094

[40] Dandona, L., et al. (2008) Risk Factors Associated with HIV in a Population-Based Study in Andhra Pradesh State of India. International Journal of Epidemiology, 37, 1274-1286. http://dx.doi.org/10.1093/ije/dyn161

[41] Sivaram, S., et al. (2008) Reasons for Seeking HIV-Test: Evidence from a Private Hospital in Rural Andhra Pradesh, India. Journal of Health Population and Nutrition, 26, 431-441.

[42] Sivaram, S., et al. (2006) HIV Prevention in India: Focus on Men, Alcohol Use and Social Networks. Harvard Health Policy Review, 7, 125-134.

[43] Weinhardt, L.S. and Carey, M.P. (2000) Does Alcohol Lead to Sexual Risk Behavior? Findings from Event-Level Research. Annual Review of Sex Research, 11, 125-157.

[44] Kalichman, S.C., et al. (2002) Sensation Seeking and Alcohol Use as Markers of Sexual Transmission Risk Behavior in HIV-Positive Men. Annals of Behavioral Medicine, 24, 229-235. http://dx.doi.org/10.1207/S15324796ABM2403_08

[45] Testa, M. (2002) The Impact of Men’s Alcohol Consumption on Perpetration of Sexual Aggression. Clinical Psychology Review, 22, 1239-1263. http://dx.doi.org/10.1016/S0272-7358(02)00204-0

[46] Madhivanan, P., et al. (2005) Alcohol Use by Men Is a Risk Factor for the Acquisition of Sexually Transmitted Infections and Human Immunodeficiency Virus from Female Sex Workers in Mumbai, India. Sexually Transmitted Diseases, 32, 685-690. http://dx.doi.org/10.1097/01.olq.0000175405.36124.3b

[47] Sivaram, S., et al. (2007) Exploring "Wine Shops” as a Venue for HIV Prevention Interventions in Urban India. Journal of Urban Health, 84, 563-576. http://dx.doi.org/10.1007/s11524-007-9196-0

[48] Rodriguez, D.C., et al. (2010) Two Sides of the Same Story: Alcohol Use and HIV Risk Taking in South India. AIDS and Behavior, 14, S136-S146. http://dx.doi.org/10.1007/s10461-010-9722-z

[49] Verma, R.K., et al. (2006) Challenging and Changing Gender Attitudes among Young Men in Mumbai, India. Reproductive Health Matters, 14, 135-143. http://dx.doi.org/10.1016/S0968-8080(06)28261-2

[50] Brockerhoff, M. and Biddlecom, A.E. (1999) Migration, Sexual Behavior and the Risk of HIV in Kenya. International Migration Review, 33, 833-856. http://dx.doi.org/10.2307/2547354

[51] Li, L., Morrow, M. and Kermode, M. (2007) Vulnerable but Feeling Safe: HIV Risk among Male Rural-to-Urban Migrant Workers in Chengdu, China. AIDS Care, 19, 1288-1295. http://dx.doi.org/10.1080/09540120701402855

[52] Tata Institute of Social Sciences and Population Council (2008) Migration/Mobility and Vulnerability to HIV among Male Migrant Workers: Maharashtra, 2008. TISS, Mumbai.

[53] Zhao, S.-l., Gao, E.-S. and Zabin, L.S. (2008) Unmet Needs for Reproductive Health Knowledge among Unmarried Migrant Youth. Journal of Reproduction and Contraception, 19, 227-238. http://dx.doi.org/10.1016/S1001-7844(08)60025-5

[54] Bam, K., et al. (2013) Sexual Behavior and Condom Use among Seasonal Dalit Migrant Laborers to India from Far West, Nepal: A Qualitative Study. PLOS ONE, 8, e74903. http://dx.doi.org/10.1371/journal.pone.0074903 
Scientific Research Publishing (SCIRP) is one of the largest Open Access journal publishers. It is currently publishing more than 200 open access, online, peer-reviewed journals covering a wide range of academic disciplines. SCIRP serves the worldwide academic communities and contributes to the progress and application of science with its publication.

Other selected journals from SCIRP are listed as below. Submit your manuscript to us via either submit@scirp.org or Online Submission Portal.
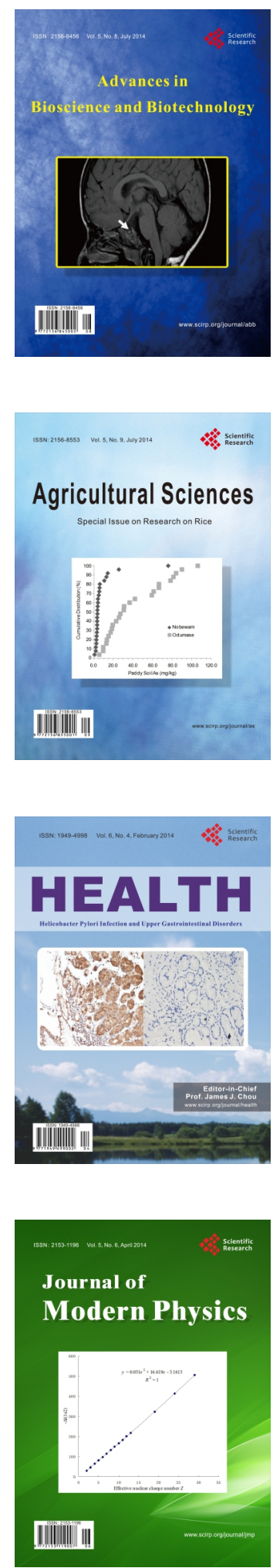
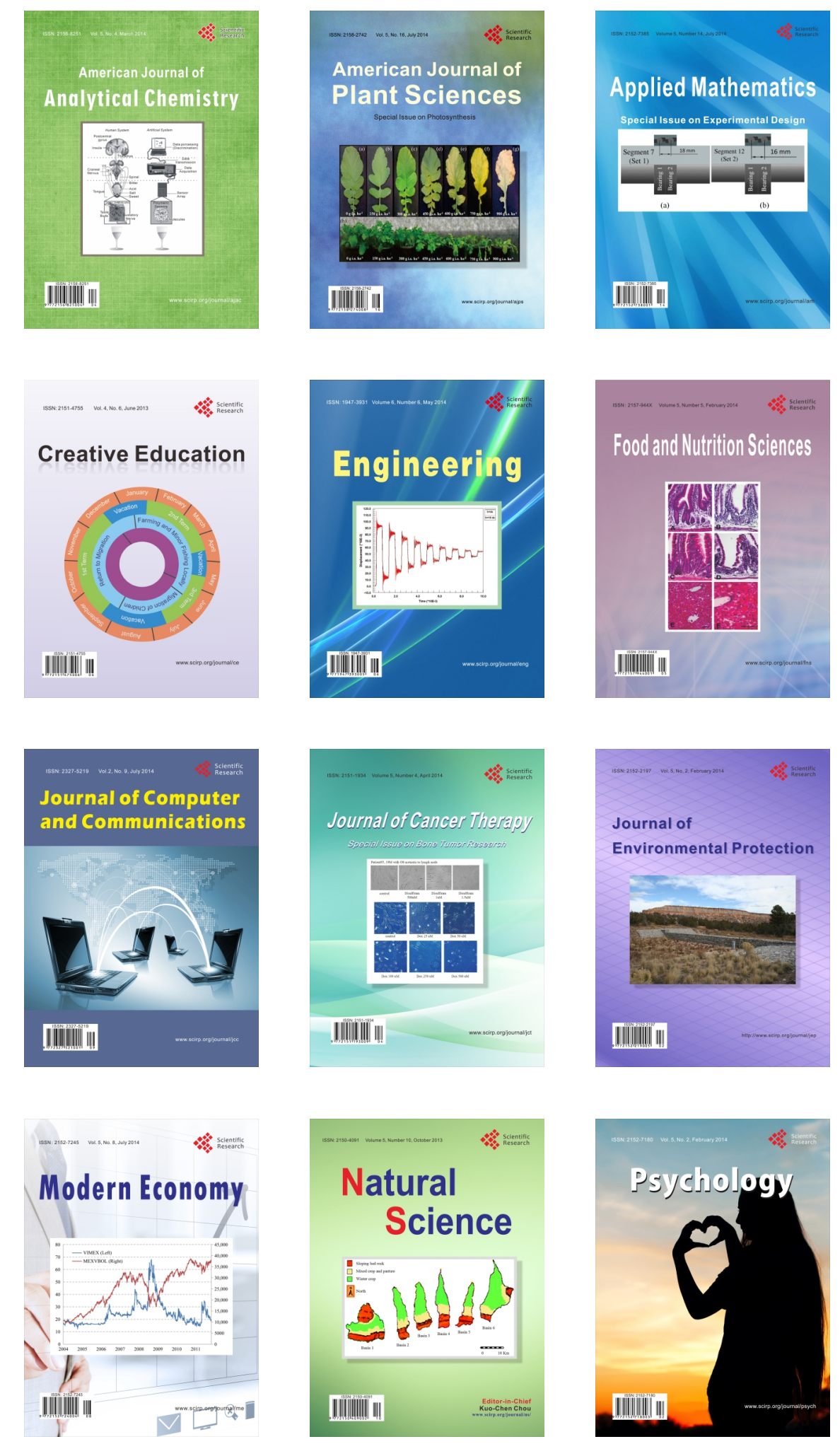